\title{
Bioética da obstinação terapêutica no emprego da hemodiálise em pacientes portadoras de câncer do colo do útero invasor, em fase de insuficiência renal crônica agudizada
}

The bioethics of therapeutic obstinacy in the use of hemodialysis in patients with invasive cervical cancer during acute-on-chronic renal failure

\author{
Carlos Henrique Debenedito Silva', Fermin Roland Schramm²
}

\section{Resumo}

Este artigo pretende discutir, do ponto de vista das ferramentas da Bioética, a indicação da hemodiálise para mulheres com câncer do colo do útero avançado com insuficiência renal obstrutiva, já tratadas por radioterapia exclusiva, ou sem mais indicação de tratamento pelo avançado estado da neoplasia, atendidas em um hospital especializado em oncologia. Pergunta-se se tais pacientes se beneficiariam desse método de substituição da filtração renal, para controle da uremia, conseqüente à progressão da doença neoplásica. Conclui-se que a utilização da hemodiálise constitui uma forma de obstinação terapêutica frente ao quadro dramático da paciente, ineficaz como medida antitumoral e incapaz de proporcionar melhor qualidade de vida à paciente. Os autores pretendem que as discussões sobre o conceito de tratamento fútil sejam estimuladas cada vez mais. A inclusão dos aspectos morais envolvidos no tratamento médico e estudados pela Bioética é vista como uma forma de analisar o impacto multifatorial da doença e do seu tratamento, quer de intenção curativa ou não, sobre a qualidade de vida dos doentes.

Palavras-chave: Bioética; Futilidade médica; Câncer do colo do útero; Insuficiência renal obstrutiva; Hemodiálise.

Monografia apresentada para a obtenção do Título de Especialista, ao final do I Curso de Especialização em Bioética e Ética Aplicada, do Instituto Fernandes Figueira, Fundação Oswaldo Cruz, Rio de Janeiro, Brasil.

${ }^{1}$ Médico Cancerologista. Especialista em Cirurgia Geral e em Oncologia. Chefe da Divisão Técnico Científica e Coordenador do Núcleo de Bioética do Hospital do Câncer IV - INCA/MS. Membro do Conselho de Bioética do Instituto Nacional de Câncer - INCA/MS.

${ }^{2} \mathrm{PhD}$. Pesquisador Titular do Departamento de Ciências Sociais, da Escola Nacional de Saúde Pública - ENSP/FIOCRUZ. Coordenador do Conselho de Bioética do Instituto Nacional de Câncer - INCA/MS. Coordenador do Curso de Especialização em Bioética e Ética Aplicada, do Instituto Fernandes Figueira - IFF/FIOCRUZ.

Endereço para correspondência: Carlos Henrique Debenedito Silva. Rua Visconde de Santa Isabel, 274 - Pilotis, Vila Isabel, Rio de Janeiro, CEP: 20560-120. E-mail: chdsilva@inca.gov.br 


\section{INTRODUÇÃO}

O esforço da Medicina na promoção e preservação da saúde das pessoas, quando levado ao extremo, pode prejudicar aqueles a quem pretende tratar e proteger. Isso é verificado quando o médico se empenha em estender a vida de um paciente além de suas possibilidades fisiológicas e de seu desejo, provocando uma situação conhecida como obstinação terapêutica, que consiste em tornar o processo de morrer uma experiência particularmente sofrida e que pode ser qualificar de "indigna", logo, questionável moralmente.

Nos últimos anos, a tecnociência e, mais recentemente, a biotecnociência trouxeram avanços inquestionáveis à Medicina, permitindo que hoje prolonguemos a vida por meio de instrumentos que proporcionam aos pacientes um suporte vital que supre as funções fisiológicas prejudicadas ou perdidas. Por isso, uma "morte indigna" será considerada aquela que vem com sofrimento e humilhação para o paciente e seu entorno familiar, sem trazer-lhe qualquer benefício, a não ser, justamente, o prolongamento de seu sofrimento, podendo prejudicar, da mesma forma, membros da família.

Assim, surge a pergunta: até quando é lícito estenderse a vida de uma pessoa dependente de aparelhos? Esta pergunta é constantemente feita, atualmente, tanto por bioeticistas como por profissionais da saúde, administradores de sistemas de saúde e até por parte da população em geral, sendo as muitas respostas dadas sempre motivo de novos questionamentos. Além disso, no Brasil, embora haja garantia constitucional à saúde, como direito de todos e dever do Estado, a escassez dos recursos acarreta problemas decorrentes da sua alocação que, de forma não eqüitativa constitui-se em razão de questionamento moral, pois seu efeito daninho sobre o sistema de saúde pode cercear ainda mais o acesso da população menos favorecida ao cuidado de sua saúde ${ }^{1-6}$.

Como conseqüência dessas discussões, uma das primeiras tentativas de resposta ao limite da intervenção médica nos pacientes, que poderão não se beneficiar de qualquer tratamento, deu-se com as alterações do conceito de morte. Tradicionalmente, considerava-se morte clínica como ausência das funções cardiorrespiratórias e, desde o final da década de 90 , adota-se prevalentemente o critério de morte cerebral, resultante da parada das funçôes cerebrais; mais especificamente o de morte encefálica (cortical ou neocortical) por cessação permanente da atividade do tronco cerebral ${ }^{7 ; 8}$.

A pergunta acerca de até onde deve ser prolongada artificialmente a vida tem provocado os médicos a novas reflexōes sobre a eticidade de sua atuação, em particular aquela sobre uma terapia que possa conduzir à questionável obstinação terapêutica, que pode ser inscrita no controvertido conceito de "futilidade"?.

A Bioética é uma ferramenta conceitual e prática que permite abordar essa distorção do papel do médico e propor soluções para evitá-la. Mas, antes de apresentar o que pode dizer a Bioética a respeito do nosso objeto, deve-se perguntar: como se determina a futilidade de uma terapia médica? A este respeito existem dois critérios aceitos: o primeiro refere-se ao tratamento que não modifica as variáveis fisiológicas do paciente; o segundo refere-se à aplicação de critérios estatísticos e considera que um tratamento é fútil quando alcança menos de $1 \%$ de chance de sucesso curativo. Para que possa receber essa classificação, sua apresentação a um Comitê de Bioética poderá, eventualmente, auxiliar na interpretação, graças ao papel analítico e prescritivo que a Bioética pretende desempenhar nas situaçóes moralmente problemáticas, e até dilemáticas, na prática médica. Com efeito, com o emprego crescente da tecnologia na área da saúde, a morte humana não somente passou a ser tecnicamente mais controlável e administrável, como de certa forma também negociável, pois os recursos destinados à saúde sendo, também em nosso país, escassos, podem permitir que sistemas públicos de saúde estabeleçam critérios para decidir que doenças possam ou, antes, devam ser tratadas ou não. Mas, por outro lado, para que não seja atribuído um caráter mercantilista aos cuidados em saúde, devem os profissionais observar uma prática médica racional, não perdulária, objetivando uma criteriosa avaliação do custo-benefício, custoefetividade e custo-utilidade. Nesse sentido, discute-se, pela visão da Bioética do Fim da Vida, o emprego da máquina de hemodiálise, como forma de substituição da função renal em mulheres com câncer do colo do útero avançado. É discutido se o emprego dessa tecnologia é entendido apenas como meio de acrescentar dias à vida dessas pessoas, e não vida aos seus dias restantes, traduzindo, ou não, uma decisão de terapia obstinada do médico.

\section{IMPLICAÇÕ̃ES DO DESENVOLVIMENTO TECNOCIENTíFICO DO SÉCULO XX}

A vigência do paradigma tecnocientífico, iniciada na segunda metade do século XIX, mas que se consolidou na segunda metade do século XX a partir do fim da $2^{a}$ Guerra Mundial, com a criação e o desenvolvimento de aparelhos e máquinas da engenharia biomédica, permitiu um avanço significativo na qualidade da vida e da saúde humana. Assim, esses progressos memoráveis culminaram no aumento do 
controle ou mesmo da cura de diversas doenças, numa melhor expectativa média de vida e no aumento da sobrevida das pessoas. Mas os novos métodos diagnósticos, tratamentos altamente sofisticados e o desenvolvimento de novas drogas propiciaram aos profissionais de saúde expor os doentes a métodos "agressivos" e esquemas terapêuticos complexos, prolongando-lhes a existência, mas a um alto custo de sofrimento humano.

Paralelamente ao desenvolvimento da medicina preventiva e do diagnóstico etiológico cada vez mais preciso das doenças, a produçáo de vacinas e os programas de cobertura populacional, a erradicação e o controle de doenças endêmicas e imunopreveníveis, além de outras medidas de saneamento básico, permitiram a redução das taxas de desnutrição e de mortalidade infantil, assim como o aumento da esperança e da qualidade de vida. Por isso, a expectativa de vida ao nascer, no Brasil, que, no início do século $\mathrm{XX}$, era de menos de 35 anos, chegou em 2000 a 68,6 anos, segundo o Censo 2000 do $\mathrm{IBGE}^{10}$. A redução das taxas de natalidade, de fecundidade, de mortalidade em idades prematuras e, conseqüentemente, o aumento significativo da população de idosos (com mais de 60 anos e correspondendo a $8,7 \%$ da população brasileira) contribuíram para a mudança, do ponto de vista demográfico, da estrutura etária da população, que se tornou mais idosa. Segundo o IBGE, o país tinha, em 1991, cerca de 13 mil pessoas com idade superior a 100 anos, passando para $24.576 \mathrm{em} 2000^{10}$.

Assim, progressivamente, aumenta o número de pessoas que passam a compor as faixas etárias que apresentam maiores riscos de desenvolver alguma forma de câncer, embora o aumento da mortalidade proporcional por câncer não se deva necessariamente ao aumento real da doença, podendo ser explicado pelo avanço nos meios de diagnóstico e tratamento, e pela redução ou controle de outras afecções.

No entanto, com a nova percepção da finitude e mortalidades humanas, proporcionadas pela incorporação acelerada de ciência e tecnologia nas práticas de saúde, novas posturas morais e éticas surgiram, pois se, por um lado, não parece razoável se opor nem descartar esses avanços, por outro pode-se questionar a idolatria da máquina, que pode sufocar o desejo de morrer em paz do indivíduo quando o tratamento se torna fútil e a morte, inevitável. De fato, a morte é parte do ciclo da vida humana, daí que cuidar do corpo que está morrendo constitui um dos objetivos da Medicina. Mas, por outro lado, o empenho da Medicina em retardar e impedir a morte é atitude lógica no esforço de lutar em favor da vida, desde que isso não prejudique sensivelmente sua qualidade. Com efeito, o contexto em que ocorre a preservação da vida e o cuidado para com o paciente são definidos pela evolução da biociência, a qual oferece novas armas para combate à dor e a agentes infecciosos; meios de diagnósticos precisos dos causadores das afecções; avanços do conhecimento psicológico - que permite aliviar as ansiedades e os sofrimentos - e o aprimoramento de máquinas mais sofisticadas na propedêutica e terapêutica, vinculando à biotécnica a substituição de órgãos comprometidos em suas funções.

\section{O SURGIMENTO DA PRIMEIRA MÁQUINA DE DIÁLISE"}

Desde a demonstração, nos anos 40, da máquina de diálise artificial dos rins, cujo crédito de inventor é do médico holandês Willem J. Kolff - que se baseou em trabalhos pioneiros do século XIX - a hemodiálise propiciou a melhoria de vida e a reversão dos sintomas de retenção das escórias urinárias nos pacientes portadores de insuficiência renal crônica. $\mathrm{Na}$ realidade, Kolff ${ }^{12}$ seduziu um industrial holandês a produzir o primeiro aparelho de rim artificial que teve uso clínico. Um novo modelo desenhado nos laboratórios da Universidade de Utah passou a ser produzido no Japão, por desinteresse das companhias americanas. Somente após a autorização obtida para a comercialização nos Estados Unidos, sua construção deu-se neste solo ${ }^{13,14}$.

O termo "diálise" foi cunhado em 1854 pelo químico Thomas Graham, referindo-se à difusão de cristalóides e ao movimento da água através de membrana semipermeável. Esta propriedade foi utilizada por John J. Abel, que apresentou seu "rim artificial" durante um Congresso de Fisiologia, em 1913, máquina cujo princípio de funcionamento de remoção de substâncias da corrente sanguínea de animais, como coelhos e cachorros, era baseada na perfusão de sangue por tubo com solução coloidal imersa em banho dialítico. George Haas, em 1924, realizou diálise em seres humanos, que, por dificuldades técnicas e limitado sucesso clínico, foi abandonada ${ }^{11}$.

Nos anos 60, com a técnica da diálise de longa duração e através de acesso vascular permanente, o processo tomou grande impulso, ao mesmo tempo em que outras modificações e refinamentos em componentes da máquina trouxeram melhorias e conseqüente sucesso na prática, logo se transformando no método mais prevalente para doença renal em estágio terminal.

Mas o dialisador, acoplado às melhorias clínicas nos pacientes portadores de insuficiência renal crônica, trouxe questionamentos morais acerca da seleção dos beneficiados com seu emprego, devido ao excesso de pacientes e ao pequeno número de equipamentos 
disponíveis. Em janeiro de 1962, entrou em funcionamento o Seattle Artificial Kidney Center, com capacidade de dialisar 9 pacientes em suas 3 camas. Com essa pequena capacidade de atuação e os custos muito altos, houve a criação de um Comitê de Seleção de Diálise de Seattle, a God Commission. Após a análise médica, este comitê leigo selecionava os pacientes, tendo por referência critérios apenas de mérito social: sexo, idade, status conjugal, número de dependentes, escolaridade, ocupação, potencial futuro.

Considerado "Comitê Divino", por ter o poder de decidir a sobrevivência ou não dos pacientes, foi este um dos primeiros fatos responsáveis pela origem dos Comitês de Bioética ou de Ética Hospitalar nos Estados Unidos. A este respeito, Willem Kolff questionou, na época, se "devemos aceitar o princípio de que a posição social deva determinar a seleção dos pacientes? Se devemos permitir a hemodiálise apenas em pacientes casados, que vão à igreja, têm filhos, têm emprego, bom salário e colaborem com ações comunitárias?" 15 .

Em 1964 houve a expansão para 10 máquinas, propiciando o atendimento de 47 pacientes. Com o atendimento domiciliar instituído em 1967 e, a partir de 1970, o início da diálise peritoneal, este centro foi renomeado para Northwest Kidney Center, já que passou a receber pacientes de uma área geográfica ampliada.

Até 1971 este Comitê esteve em atividade, pois só a partir de então os programas de seguro saúde e o apoio financeiro do estado de Washington permitiram que todos os indicados fossem igualmente tratados.

\section{APRESENTAÇÃO DO CENÁRIO ONCOLÓGICO}

$\mathrm{O}$ câncer ginecológico e, em especial, o do colo do útero, continua a ser, entre nós, um sério problema. Embora possa ter uma prevenção efetiva na detecção das lesões pré-malignas, em realidade continua a ser causa considerável de mortalidade no Brasil e em outros países em desenvolvimento ${ }^{16-18}$. Aqui, em 1979, a taxa de mortalidade registrada era de 3,44/100.000, enquanto em 2000 era de 4,59/100.000, correspondendo a uma variação percentual relativa de mais $33,1 \%$. Para 2002, a estimativa de óbitos e casos novos esperados era de, respectivamente, 4.005 e 17.600 , correspondendo às taxas brutas de mortalidade e incidência de 4,49/100.000 e $19,82 / 100.000^{19}$.

Considerando-se que os estágios avançados, II a IV, da Federação Internacional de Ginecologia e Obstetrícia / $\mathrm{FIGO}^{20}$, têm como terapia exclusiva a radioterapia, entre $60 \%$ e $70 \%$ das pacientes matriculadas no Serviço de Ginecologia do INCA, já se encontrando nessa situação, receberam essa forma de tratamento ${ }^{21}$. Infelizmente, o insucesso do tratamento nestes casos, em cinco anos, é expressivo, não havendo abordagem terapêutica oncológica específica eficiente quando isso ocorre $^{21}$.

Recentemente, dois criteriosos estudos clínicos, considerados marcos na literatura médica oncológica, passaram a estimular o uso da quimioterapia para o tratamento concomitante à radioterapia, em pacientes portadoras de neoplasia maligna invasora do colo do útero. No primeiro deles ${ }^{22}$, foram analisadas mulheres em estágios avançados da doença, e no outro ${ }^{23}$ mulheres em seu estágio inicial, mas com doença volumosa (tumores limitados ao colo de útero com $4 \mathrm{~cm}$ ou mais de diâmetro), seguidas de histerectomia adjuvante. Os resultados da terapêutica combinada foram melhores do que com a radioterapia isolada, estimulando os centros de tratamento oncológico a empregá-los.

Hopkins \& Morley $^{24}$ avaliaram retrospectivamente 175 pacientes, entre 1970 e 1985 , estratificadas segundo os estágios III e IV, no Centro Médico da Universidade de Michigan e tratadas exclusivamente por radioterapia (teleterapia e braquiterapia ou teleterapia com dose de reforço, caso a braquiterapia não tivesse sido realizada). Os autores observaram dois principais fatores prognósticos cumulativos para a sobrevida em cinco anos: o primeiro foi o estado da função renal, com alto significado preditivo cumulativo quando sem alteração anatômica, ou já com hidronefrose uni ou bilateral; o segundo, a extensão para linfonodos, com relação direta com o número dos acometidos, quer em cadeia pélvica isolada, quer em conjunto com a cadeia paraaórtica. Especificamente em relação ao primeiro fator, quando a pielografia venosa era normal, $47 \%$ das pacientes sobreviveram, mas, quando a obstrução ureteral era presente ainda sem falha renal, a taxa caiu para $29 \%$. Havendo obstrução ureteral e falha renal $(n=18)$, todas morreram da doença em 16 meses. Nestas pacientes, a drenagem renal foi estabelecida em 15 delas, com sobrevida média de oito meses, tendo $66 \%$ morrido da doença dentro de um ano. Preferencialmente foi utilizada a nefrostomia percutânea e, antes de sua disponibilidade, por método aberto. As três pacientes que se recusaram ao by-pass renal faleceram em até três meses.

As pacientes que apresentam câncer do colo do útero avançado ainda não tratado, mas já em insuficiência renal, ou quando se tornam anúricas durante o tratamento pelas irradiações, são comparadas clinicamente àquelas que apresentam recidiva tumoral após tratamento, com insuficiência renal. Nessa condição comum de falha renal, pode-se empregar uma, ou mais, das alternativas disponíveis para a melhoria da função renal: (1) cuidados médicos: restrição do volume de ingestão de água, proteínas, potássio e sódio; dieta 
hipercalórica, rica em carboidratos e gorduras, para minimizar o estado catabólico e administração de resina de troca iônica, digitálicos e, ocasionalmente, diuréticos; (2) diálise peritoneal intermitente ou hemodiálise intermitente; (3) derivação cirúrgica da obstrução ureteral: cateterização ureteral retrógrada isolada ou, precedendo uma nefrostomia aberta ou, mais recentemente, por via percutânea. Qualquer dos métodos derivativos tem sua morbidade e sua mortalidade, decorrentes da necessidade de longa hospitalização e do ajustamento psicológico da paciente ao seu estado de saúde ${ }^{25}$.

A abordagem médica nesse momento requer decisão balanceada entre a qualidade de sobrevida da paciente e a morbidade envolvida, pois seu prognóstico nessa condição é pobre. Mesmo levando-se em consideração as modernas técnicas de radioterapia radicais, a inclusão da quimioterapia como alternativa em tempo recente, entretanto de benefício ainda reservado, e a exenteração cirúrgica apenas para doença recorrente intravaginal, as taxas de sobrevida são baixas.

Das alternativas para insuficiência renal, a nefrostomia percutânea tem larga citação na literatura urológica, mas nem tanto em ginecologia oncológica. Foi primeiramente descrita por Goodwin, Casey \& Woolf ${ }^{26}$. Seu emprego em doença maligna é controverso e depende de uma variedade de fatores, principalmente de uma apurada análise do tipo e estadiamento do tumor e seus fatores prognósticos para uma conseqüente boa qualidade de vida da paciente. Mann et al. ${ }^{27}$ discutiram o uso da nefrostomia percutânea, após sua utilização em 14 pacientes com câncer do colo do útero, em fase prévia ao tratamento ou com doença recorrente. Compararam seus resultados aos de Taylor $\&$ Andersen ${ }^{28}$ e concluíram, igualmente, que as medidas clínicas, para o pronto início da terapia, possivelmente por irradiação, trariam melhores resultados. A punção renal ficaria reservada para as pacientes com falha na abordagem clínica e, como tratamento prévio, para pacientes com doença recorrente, quando acreditavam serem candidatas à quimioterapia agressiva.

Watkinson et al. ${ }^{29}$ analisaram 50 pacientes de ambos os sexos, com doença abdominopélvica maligna, com obstrução renal, no intuito de estabelecer critério da indicação da nefrostomia percutânea. Levantaram o tempo de sobrevida e a qualidade de vida, e concluíram que nenhum benefício houve no uso como medida paliativa.

No Brasil, foi realizada uma análise de 129 prontuários de pacientes com neoplasia maligna do colo do útero invasora, de um hospital especializado em
Oncologia, internadas e hemodialisadas por insuficiência renal, entre janeiro de 2000 e dezembro de 2003. Levouse em conta a descrição do estado geral na admissão, os resultados de exames laboratoriais e de imagem, tempo de permanência hospitalar (a alta, muitas vezes, coincidindo com o óbito) e o número de sessões dialíticas $^{1}$. Nessa avaliação, o emprego da alternativa de substituição da função renal, nessas doentes, não trouxe benefício do ponto de vista clínico, nem no controle da doença neoplásica, ocasionando, outrossim, demora na utilização das medidas paliativas mais apropriadas e disponíveis. Daí poder-se considerar que sua adoção, nessas condições, se constituiu em obstinação terapêutica.

\section{ABORDAGENS DOS DOENTES COM DOENÇA TERMINAL}

$\mathrm{Na}$ Cancerologia, a incorporação de novas tecnologias, os programas de detecção precoce, o acompanhamento epidemiológico e os indicadores de qualidade de vida (QUALY) importam nas decisōes de política de saúde pública referentes à alocação de recursos e à incorporação de novos medicamentos e equipamentos. O aumento das doenças nãotransmissíveis, como o câncer, com altos índices de morte, transformou estas doenças em um problema de saúde pública de dimensões nacionais e mundiais.

Mudanças de hábitos, aumento da expectativa de vida da população, disseminação do tabagismo, além de fatores ligados à industrialização e à urbanização, bem como o deslocamento do homem do campo para a periferia das cidades grandes, acentuando a desigualdade entre as classes sociais, constituem-se em grandes componentes da geração das doenças crônicodegenerativas. Por essas razões, diz-se ser o câncer uma doença do desenvolvimento e da civilização ${ }^{3}$.

A incorporação tecnológica é bem-vinda quando melhora resultados já estabelecidos ou resgata doentes refratários aos tratamentos em voga. Mas deve-se lembrar que não há tratamentos sem riscos, nem sem efeitos colaterais. Por isso, o emprego de um novo tratamento, quando sob análise econômica, deve atender a critérios de efetividade (funciona?); eficiência (o quão bem funciona?); eficácia (a que custo funciona bem?) e eqüidade (funciona bem a que custo e para quantos?) ${ }^{30}$.

O emprego da hemodiálise em doentes renais crônicos tem seu lugar assegurado como norma de conduta clínica universal. Sua aplicação tem por princípio a substituição da função renal perdida e justifica-se por manter o doente viável à espera de um transplante renal, que lhe assegurará a sobrevivência. A obstrução ureteral, de origem extrínseca aos rins,

\footnotetext{
${ }^{1}$ Dados não publicados, em posse dos autores.
} 
independente da doença de base, acarreta, via de regra, prejuízos na função renal que, se não passageira, leva a um quadro de insuficiência progressiva. Assim, a aplicabilidade da hemodiálise é incontestável em doenças crônicas ou em fase pré-operatória de doenças cirúrgicas, inclusive neoplásicas, que culminam com a insuficiência renal. Várias são as condições clínicas em que os pacientes podem se beneficiar da hemodiálise, por insuficiência renal aguda ou crônica: diabetes mellitus, hipertensão arterial, doença coronariana, insuficiência cardíaca congestiva, cardiomiopatia, arritmias cardíacas, doenças cerebrovasculares, doença vascular periférica, anemia, osteodistrofia renal, doenças infecciosas, síndrome do túnel do carpo, artrite reumatóide, miastenia grave, grandes queimados, doenças pulmonares crônicas, tabagismo, neoplasia e lúpus eritematoso sistêmico ${ }^{25}$.

Nos doentes crônicos, a hemodiálise traz benefícios clínicos pelo equilíbrio hidroeletrolítico e pela diminuição da uremia, tornando possível a continuidade da vida. Contudo, sérias limitaçôes físicas, sociais e psicológicas são relacionadas à dependência da máquina de hemodiálise.

Reichsman \& Levy ${ }^{31}$ identificaram os três estágios em que são enquadrados os doentes renais crônicos, a partir do início das sessões de hemodiálise: o primeiro, o da "lua de mel", com o renascer da esperança e da confiança, pela melhora física e emocional; o segundo, o período do descontentamento e do desencanto, quando a dependência da máquina fica clara; por fim, o período da adaptação, do equilíbrio e aceitação das limitações, deficiências e dependências do procedimento.

Por analogia, é lícito supor que o emprego da hemodiálise na insuficiência renal crônica agudizada traga benefícios às pacientes, como método alternativo da função renal de excreção urinária. Do ponto de vista clínico-laboratorial não cabe discussão. Mas, por conta de sua doença de base (neoplasia do colo do útero avançada), impóe-se que o procedimento seja realizado durante internação hospitalar. $\mathrm{O}$ acompanhamento ambulatorial da paciente nem sempre leva o médico a suspeitar de um quadro de insuficiência renal crônica, pois esta se instala de modo insidioso. Uma vez diagnosticado o quadro urêmico, o médico indica a filtragem externa. Entretanto esta decisão, de cunho beneficente, quase sempre não leva em conta a avaliação do estado da doença neoplásica maligna de base. Da mesma forma, pode haver pressão familiar por instrução externa (é comum, pois a paciente recebe atendimento prévio em unidades hospitalares de emergência) ou, mais recentemente, por conseqüência de ordens judiciais.

A hemodiálise nas pacientes com insuficiência renal por doença neoplásica avançada, em fase pré-tratamento, é pouco descrita, existindo maior utilização da derivação externa por punção percutânea - nefrostomia percutânea. Este procedimento tem resposta objetiva na melhoria do quadro urêmico conseqüente ao processo obstrutivo, até que a realização do tratamento primário ocorra. Como tratamento paliativo, a nefrostomia percutânea pode ser apropriada em casos selecionados, quando prolonga a expectativa de vida, controlando graves desequilíbrios clínicos ou permite à paciente retornar à sua casa com uma melhor qualidade da vida remanescente $\mathrm{e}^{32}$.

\section{Avaliação BIOÉTICA: BENEFIIÊNCIA, NÃO-MALEFIĈNNCIA E QUALIDADE DE VIDA DO DOENTE TERMINAL}

Cabe ao médico, na sua atuação em princípio beneficente, avaliar se alguma alternativa para a recuperação da função renal insuficiente pode ser utilizada. Da mesma forma, cabe-lhe avaliar se essa intervenção beneficiará de fato, ou não, a paciente. Cada vez mais, a valorização da autonomia da paciente e o peso moral do seu consentimento na decisão de tratamento devem ser ponderados, e o equilíbrio entre os dois princípios deve ser procurado. A discussão versa entre o direito da paciente em escolher ou recusar seu tratamento, e esta decisão ser, ou não, limitada pelo dever do médico em praticar sua responsabilidade profissional. No entanto, entende-se que o médico tem o direito de recusar iniciar tratamentos fúteis, baseado nos seus conhecimentos técnicos sobre os efeitos e impactos na qualidade de vida do paciente, mesmo frente ao pedido deste, ainda que em fase terminal, requeira tal tratamento.

Considera-se paciente terminal aquele que está em fase final por evolução de sua doença, sem mais condiçôes de reversibilidade, mesmo que parcial e temporária, frente a qualquer medida terapêutica conhecida e aplicada. Como tal, necessita de cuidados paliativos que facultem o máximo de conforto e bemestar até o óbito. Nessa condição clínica, o tratamento oncológico específico antitumoral não mais cabe, pois a partir desse momento a preservação da qualidade de vida ganha prioridade sobre a preservação da vida, sendo que a percepção dos próprios doentes da sua condição real associa sua morte a um curto espaço de tempo. Essa discussão tomou importância, levando a própria Organização Mundial da Saúde a definir saúde como "um estado de completo bem-estar físico, mental e não meramente a ausência de doença ou enfermidade" 33 , incluindo no conceito de saúde ter-se qualidade de vida adequada. De fato, na fase inicial do tratamento, o foco da atenção está direcionado para o combate ao tumor 
e, por conseqüência, na preservação da saúde e da vida.

Assim sendo, de um ponto de vista intuitivo, o princípio bioético da beneficência é, via de regra, prevalente, ainda que, de um ponto de vista crítico, já se dava perguntar se, de fato, preservar a vida coincide com beneficência. Mas, quando houver evolução da doença, e não mais se falar em curá-la ou controlá-la, e sim em minimizar o sofrimento pela paliação, o princípio da não-maleficência deve ser priorizado. Nessa situação, fazer todo o possível para beneficiar o paciente pode significar prejudicá-lo, visto que o suposto benefício, na realidade, transforma-se em malefício, por causar ou prolongar o sofrimento. Nesse momento, a qualidade de vida ganha destaque e, sobretudo, prioridade sobre o prolongamento da vida enquanto tal, tendo a família e o ambiente papéis relevantes no atendimento ao doente. Em outros termos, quando o paciente deixar de ser salvável, e passar a fazer parte do tempo de decurso da morte inevitável, embora impreciso no que se refere ao momento, estamos frente a um paciente chamado, de modo impróprio, de "terminal". Nessa etapa, a ponderação entre os dois princípios bioéticos da nãomaleficência e da beneficência sugerem que se deva objetivar o alívio da dor e do sofrimento, não causando danos, de acordo com o princípio hipocrático primum non nocere, que adquire uma prioridade léxica sobre o bonum facere. Com efeito, o exercício do médico e dos demais membros da equipe de saúde é calcado em duas grandes atitudes morais: a preservação da vida e o alívio do sofrimento. Na maior parte das vezes, as duas atitudes não entram em conflito e até se completam. Entretanto, em alguns casos, podem se tornar antagônicas, pois, se houver opção pela preservação da vida a qualquer custo e por qualquer meio, estar-se-á infligindo sofrimento desnecessário e, portanto, desrespeitando o princípio da não-maleficência. Como afirma Jean-Robert Debray (apud Pessini ${ }^{34}$ ): "o comportamento médico que consiste em utilizar processos terapêuticos cujo efeito é mais nocivo do que os efeitos do mal a curar, ou inútil, porque a cura é impossível e o benefício esperado é menor que os inconvenientes previsíveis" define as atitudes médicas que, visando salvar a vida do paciente terminal, submetem-no a grande sofrimento, não se prolongando a vida digna de ser vivida, e sim o processo de morrer, isto é, a obstinação terapêutica.

Como se observa, o progresso técnico-científico trouxe benefícios ao exercício da Medicina. Mas, na medida em que passou a interferir na fase final da vida humana, incorporou um novo problema ético: a atuação desmedida da equipe médica. Mesmo visando trazer menos sofrimento, dignidade à vida e à morte, por maior conhecimento biológico, formulações analgésicas mais potentes contra a dor, máquinas mais sofisticadas na substituição de órgãos em disfunção e maior conhecimento psicológico no alívio das ansiedades, toda essa tecnociência não teve sucesso nesse intento. Dilemas éticos, escolhas difíceis, angústias, ambivalência e incertezas aparecem estampados no dia-a-dia. Em suma, não se trata de ser contra o progresso, e sim de sabê-lo usar em benefício do homem.

A morte não pode ser concebida na Medicina como falha, pois sendo parte do ciclo da vida humana, uma vez perdida a preservação e restauração da saúde primeiro objetivo de toda a arte médica - o cuidado com a qualidade de vida deve ser o último resultado desse esforço (aliás, presente desde a etapa inicial). O prolongamento exagerado e o sofrimento da morte do paciente, numa abordagem terapêutica inútil, que não permite o desfecho da vida, são considerados distanásia (do grego "dis" - afastamento + "thanatos" - morte), isto é, a manutenção da vida humana, considerada o único valor, com a utilização de todos os recursos nesse intuito, podendo implicar encarnizamiento, obstinação ou futilidade terapêuticos.

Em outros termos, se for considerada a definição de saúde apenas como a ausência de doença e a morte o grande inimigo a derrotar, o importante passa a ser a manutenção da vida, sendo sua qualidade um parâmetro relegado para segundo plano. Assim sendo, as discussōes ficam entre a utilização do desenvolvimento técnico e a questão ética decorrente. Nessa discussão aparecem aqueles que defendem a eutanásia. Termo vindo do grego "eu" - boa, apropriada - e "thanatos" - morte - proposto por Francis Bacon, em 1623, em sua obra "Historia Vitae et Mortis" (apud Goldim ${ }^{35}$ ), como forma de eliminar a dor e o sofrimento, devolvendo a dignidade ao doente crônico ou terminal. Em sua defesa, Thomas More (apud Lepargneur ${ }^{36}$ ) já opinara na sua famosa obra Utopia, em 1516. Se a eutanásia contrapóe-se à distanásia, esta, com o emprego da tecnologia no prolongamento inútil da vida com o paciente já em estado final, fez surgir o termo ortotanásia ${ }^{37}$. Palavra vinda do grego "orto" - correta - e "thanatos" - morte, que significa a morte no tempo certo, sem abreviação nem prolongamentos precários e penosos da vida, sem, contudo, interromper os cuidados normais, ordinários, aos doentes. Neste sentido, a ortotanásia parece estimular a humanização da morte e o alívio das dores, sem obrigar o uso de medidas abusivas que levem a um aumento de sofrimentos adicionais e inúteis.

\section{PACIENTE E SEU ENFRENTAMENTO DA DOENÇA}

A doença do paciente portador de câncer modifica sua vida, quase sempre radicalmente. $\mathrm{O}$ momento da 
confirmação de seu diagnóstico, o tratamento sob qualquer forma, sua recuperação e a notícia final do sucesso, ou não, são acompanhados de uma expectativa particular para cada etapa. A trajetória da doença proporciona variadas respostas emocionais que são fundamentais em sua compreensão ${ }^{38}$. Inicialmente, quando o paciente e sua família sabem da nova realidade, a interpretação variará segundo a forma pessoal ou coletiva de entendê-la e enfrentá-la. É o processo de realização. Tendo seu primeiro diagnóstico confirmado, a interpretação dada pelo doente é uma "sentença de morte", o que impõe ao mesmo uma etapa de luta pela cura. É o período da batalha, que vai dos exames para o estadiamento até a conclusão do tratamento, recebendo as maiores esperanças e expectativas. Com o sucesso do tratamento, inicia-se o período da apreensão. Cada consulta de revisão ou controle é antecedida do medo de que esta possa trazer notícias ruins; se, e, quando ocorrer recidiva da doença, o ciclo reiniciar-se-á, desde que haja tratamento reserva a ser instituído. Caso não, virá a etapa do óbito, quando todos tomam conhecimento da condição evolutiva e terminal da doença. Será o segundo diagnóstico $^{39}$, último, na leitura do paciente e sua família. Elisabeth Kübler-Ross ${ }^{40}$ lista os estágios emocionais observados nos pacientes, como sendo: negação, ira, barganha, depressão e aceitação, qualquer que seja a ordem de apresentação. Uma vez caracterizada a doença em evolução, o paciente enfrenta duas tarefas ao preparar-se para a morte: a primeira, de foro intrapsíquico, quando se despede de si mesmo; e a segunda, quando sua vida interpessoal, em várias frentes é checada. Relações sociais, espirituais, resoluções financeiras e de projetos de vida, na medida do possível, devem ser terminadas. Dificuldades decorrentes da dor, que poderá ser insuportável, acarretarão mudanças nessas finalizações.

Se, a princípio, a figura central do médico, individualmente, coordenara o tratamento, agora ele será substituído por uma equipe multiprofissional que, na soma das experiências, passará a cuidar do paciente e de seus familiares no combate dos sintomas, paliando o sofrimento.

\section{HOSPICES - CUIDADO PALIATIVO COM QUALIDADE}

$\mathrm{Na}$ medicina paliativa do hospice moderno, de acordo com o modelo proposto por Cicely Saunders, quando em 1967 fundou o St. Christopher's Hospice, em Londres, as pessoas são cuidadas nas fases finais de uma doença terminal. Esse processo é encarado, normalmente, priorizando-se o controle da dor e dos sintomas, objetivando melhorar a qualidade de vida. A filosofia do movimento hospice propõe: uma assistência voltada para o cuidado paliativo e não para o terapêutico da enfermidade básica; a aceitação de uma morte digna para o paciente; e atenções às necessidades sociais e psicológicas do doente e de sua família. Nesse momento dois questionamentos são feitos:

1 - Quando o tratamento deve ser interrompido e iniciado o cuidado paliativo?

2 - A filosofia aplicada no trabalho paliativo deve ser absorvida por outras áreas da Medicina?

Essa discussão pode representar um dilema ético na Medicina, pelo significado do prolongamento da vida de um paciente com doença em estágio avançado, principalmente após o desenvolvimento tecnológico da ciência médica. Quando a decisão for de não prolongar, a qualquer custo, a vida de um paciente em seu final, a morte poderá oferecer menos dor e sofrimento. Daí mais dignidade. Assim, surge uma situação difícil para alguns profissionais: ser mais importante a manutenção da quantidade de vida, do que da sua qualidade.

Para melhor se identificar esse limite entre tratamento e cuidado, MacDonald ${ }^{41}$ apresenta quatro fases da abordagem do câncer: (1) prevenção da doença com políticas de saúde e educação públicas; (2) prevenção da doença avançada com programas de diagnóstico precoce; (3) prevenção da morte com tratamento anticâncer; (4) prevenção do sofrimento realizada pelo grupo de cuidado paliativo. Este autor defende que é enganosa a idéia de que a $4^{a}$ etapa deva ser associada apenas ao cuidado final do tratamento anticâncer. Sua associação, muitas vezes desde o momento do diagnóstico, possibilitará a melhor qualidade de vida possível para o paciente e sua família. A falha da terapia do paciente já em estágio avançado de câncer poderá ser mais bem estimada com essa aproximação, de acordo com a própria definição da Organização Mundial da Saúde para medicina paliativa: "é o cuidado total e ativo de pacientes cuja doença não mais responde ao tratamento curativo, no qual são da maior importância: o controle da dor e de outros sintomas, como também os problemas psicológicos, espirituais e sociais, pois o objetivo do cuidado paliativo é a aquisição de uma melhor qualidade de vida para os pacientes e seus familiares, e muitos aspectos do cuidado paliativo são também aplicáveis antecipadamente, no decorrer da doença e juntamente com o tratamento anticâncer" ${ }^{42}$.

Por isso, no segundo questionamento, se a arte médica e a ciência dos cuidados paliativos devem interagir, vários profissionais almejam que isso ocorra em todas as áreas da Medicina para benefício dos doentes terminais, quer atendidos em casa, no hospital ou num lar para idosos. Uma equipe multiprofissional poderá oferecer cuidados globais às pacientes. Twycross ${ }^{43}$ 
define quatro metas importantes a serem alcançadas pela equipe que trabalha com os pacientes nos hospices: alívio de dor ou outros sintomas que tragam sofrimento; cuidados psicológico e espiritual na preparação da morte; apoio para ter suas atividades próximas do normal com autonomia; integridade e auto-estima; e, por fim, para a família, suporte durante a doença do familiar e no luto. Nos hospices são acolhidos pacientes e familiares para que vivam em condições de conforto pleno, tanto quanto possível, por lidarem com doença incurável, morte e dor da perda. Utiliza-se uma abordagem multidisciplinar (médico, enfermagem, fisioterapeuta, assistente social, nutricionista e psicólogo) para atender às necessidades físicas, emocionais, espirituais e sociais dos pacientes e familiares.

O princípio moral de respeito à dignidade da pessoa, que inclui o conceito de integridade, é básico para o cuidado dos pacientes pela medicina paliativa. Implica no compromisso de controlar a dor e minorar o sofrimento, na continuidade da atenção médica, sem abandono do paciente, respeitando as decisões acerca de seu cuidado, a valorização de sua pessoa, com seus sentimentos, pensamentos, medos, esperanças, e demais valores.

\section{CONCLUSÃO}

A Bioética, ramo aplicado da filosofia moral, considerada campo interdisciplinar normativo porque se preocupa com as normas da conduta humana, é uma proposta em favor do bem-comum e de cada um, e por isso não pode ser desvinculada do conjunto das necessidades individuais e coletivas, entendidas não de maneira abstrata, mas concreta; isto é, referida à qualidade de vida dos indivíduos e coletivos reais. Em outros termos, a Bioética faz parte de um sistema de forças que conduzem o homem pelo caminho, ou métodos, da luta pela liberdade e pela justiça social, mesmo que prima facie os dois objetivos pareçam antitéticos. Por isso, a Bioética não pode ser uma opção neutra e acomodada, estéril e formalista, complacente com uma estrutura social perversa, que cria profundos desníveis e golpeia a comunidade de forma cruel e impiedosa, nem com uma estrutura narcísica, que isola o indivíduo da estrutura da subjetivação, isto é, da norma que o individualiza junto com os outros. Neste sentido, a Bioética deve ser entendida como a guia de um projeto capaz de atingir os mais amplos setores da sociedade, formados por indivíduos, principalmente os mais desamparados frente à iniqüidade e ao sofrimento.

Passou-se o tempo em que a ética era apenas um elenco de decisões pessoais, reais ou supostamente interiorizadas, ou desempenhando simples papel de etiqueta do profissional. Se ela não for sensível às modificações propostas pela concepção evolutiva ou histórica que se tem da sociedade e dos humanos que a compõem, será apenas uma norma pobre e mesquinha. Por isso, tudo leva a crer que há motivos políticos e sociais emergentes que começam a dar forma às reclamaçōes contra a prática médica mais antiga, surda aos pedidos humanos para uma melhor qualidade do viver e do morrer, posiçôes mais coerentes com a realidade em que vivem as pessoas e populaçōes reais de nossa época.

Daí a necessidade de uma "ética da vida" capaz de alcançar cada vez mais a pessoa do homem de agora, denunciando os seus dramas, vivenciados pela maioria, tendo como origem a injustiça e a iniqüidade. Se for razoável afirmar que a ética tem como fim fazer com que a vida seja uma vida boa (como pretendia Aristóteles), mas também que, para isso, ela precisa de pessoas que devem saber qual é seu dever (como queria Kant), cabe à ética fundamentar tudo o que deve o homem ser, e o que é bom que faça.

Concluindo, o objeto material da Ética são os atos humanos, livres e responsáveis, que pode ser constituído de modo tanto perfeito quanto imperfeito, mas que, além de sua suposta base na vontade boa kantiana, deve ainda poder dar conta de seus efeitos em termos de vida boa ou ruim, como pretendia Aristóteles, o Estagirita.

$\mathrm{Na}$ atividade médica, os componentes técnicos, aliados ao respeito ético, devem ser vistos como o ideal profissional, com perfeito equilíbrio entre o conhecimento científico, a habilidade técnica e a sensibilidade ética, as quais sempre estarão na corda bamba do julgamento pelo outro afetado, positivo ou negativamente em sua vida humana, ou demasiada humana.

Neste artigo, os autores analisam e discutem, do ponto de vista bioético, a utilização de um procedimento invasivo (hemodiálise como forma de tratar a insuficiência renal aguda por obstrução tumoral externa, em mulheres com câncer do colo do útero avançado), que poderá ser meio de tenacidade médica, sem apresentar benefício às pacientes, muito ao contrário, constituindo-se em obstinação médica.

\section{REFERÊNCIAS}

1. Callahan D. False hopes: overcoming the obstacle to a sustainable medicine. New Brunswick: Rutgers University Press; 1999.

2. Gadelha MIP. Planejamento da assistência oncológica: um exercício de estimativas. Rev Bras Cancerol. 2002;48(4):533-43.

3. Kligerman J. O câncer como um indicador de saúde no 
Brasil. Rev Bras Cancerol. 1999;45(3):5-8.

4. Kligerman J. O desafio de se implantar a assistência oncológica no SUS. Rev Bras Cancerol. 2000;46(3):235-39.

5. Kligerman J. Fundamentos para uma política nacional de prevenção e controle do câncer. Rev Bras Cancerol. 2002;48(1):3-7.

6. Schramm FR, Pinto ER, Gadelha MIP, Sigaud MA, Arreguy E. Jornada de Bioética em assistência oncológica. Rev Bras Cancerol. 2000;46(4):359-66.

7. Gogliano D. Pacientes terminais - morte encefálica. Bioética. 1993;1. [acesso em out 2003]. Disponível em: <http:// www.portalmedico.org.br/revista/bio $2 \mathrm{v} 1 /$ pacienterm.html>

8. Schramm FR. A questão da definição da morte na eutanásia e no suicídio assistido. O Mundo da Saúde. 2002;26(1):178-83.

9. Mota JAC. Quando um tratamento torna-se fútil? Bioética. 1999;7. [acesso em set 2003]. Disponível em: <http:// www.portalmedico.org.br/revista/biolv7/quando.htm>

10. Instituto Brasileiro de Geografia e Estatística (IBGE). Censo Demográfico 2000. [acesso em set 2003]. Disponível em: <http://www.ibge.gov.br>

11. Eknoyan G. Dialysing for life: the development of artificial kidney, by Jacob van Noordwijk. 114pp., Boston, Kluwer Academic, 2001 (book review). New Engl J Med. 2001;345(11):844-45.

12. Kolff WJ. [cited 2003 Mar 3]. Available from:: <http:// www.standford.edu/dept/HPS/transplant/html/ kolff.html>

13. KolffWJ, Berk HThJ, Ter Welle M, Van Der Ley AJW, Van Dyk EC, Noordwijk J. The artificial kidney: a dialyser with a great area. Acta Med Scand. 1944;117:120.

14. KolffWJ. First clinical experience with the artificial kidney. Ann Intern Med. 1965;62(3):608-19.

15. Childress JF. Who shall live when not all can live? In: Edwards RB, Graber GC. Bioethics. Chicago: Harcourt, 1988:749, apud Goldim JR, Francisconi CF. Os comitês de ética hospitalar. Bioética. 1998;6. [acesso em set 2003]. Disponível em: <http://www.portalmedico.org.br/revista/ bio2v6/cometicahosp.htm>

16. Ferlay J. Processing of data. In: Parkin DM, Whelan SL, Ferlay J, Raymond L, Young J (eds). Cancer Incidence in five continents. Vol. VII. Lyon: IARC Scientific Publications; 1997(143);58-62.

17. Pisani P, Parkin DM, Bray F, Ferley J. Estimates of the worldwide mortality from 25 cancers in 1990 . Intern J Cancer. 1999;83:18-29.

18. Parkin DM, Bray FI, Devesa SS. Cancer burden in the year 2000. The global picture. Eur J Cancer. 2001;37 (8 Suppl):S4-S66.

19. Ministério da Saúde / Brasil. Estimativas da incidência e da mortalidade por câncer. Rio de Janeiro: Instituto Nacional de Câncer; 2002.
20. Benedet JL, Odicino F, Maisonneuve P, Beller U, Creasman WT, Heibtz APM, et al. Carcinoma of the cervix uteri. J Epidemiol Biostatistics. 2001;6:5-44.

21. Condutas do INCA/MS. Câncer do colo do útero. Rev Bras Cancerol. 2000;46(4):351-54.

22. Rose PG, Bundy BN, Watkins EB, Thigpen JT, Depp G, Maiman MA, et al. Concurrent cisplatin-based radiotherapy and chemotherapy for locally advanced cervical cancer. $\mathrm{N}$ Engl J Med. 1999;340:1144-153.

23. Keys HM, Bundy BN, Stehman FB, Muderspach LI, Chafe WE, Suggs III CL, et al. Cisplatin, radiation, and adjuvant hysterectomy compared with radiation and adjuvant hysterectomy for bulky stage IB cervical carcinoma. New Engl J Med. 1999;340(15):1154-161.

24. Hopkins MP, Morley GW. Prognostic factors in advanced stage squamous cell cancer of the cervix. Cancer. 1993;72:2389-393.

25. Davison AM, Cameron JS, Grünfeld JP, Kerr DNS, Ritz E, Wineards CG, editors. Oxford Textbook of Clinical Nephrology. New York: Oxford University Press; 1998.

26. Goodwin WE, Casey WC, WoolfW. Percutaneous trocar (needle) nefrostomy in hidronephrosis. JAMA. 1955;157:891-94.

27. Mann WJ, Hatch KD, Taylor PT, Partridge EM, Orr JW, Shingleton HM. The role of percutaneous nephrostomy in gynecologic oncology. Gynecol Oncol. 1983;16(3):393-99.

28. Taylor PT Jr., Andersen WA. Untreated cervical cancer complicated by obstructive uropathy and oliguric failure. Gynecol Oncol. 1981;11(2):162-74.

29. Watkinson AF, A'Hern RP, Jones A, King DM, Moskovic EC. The role of percutaneous nephrostomy in malignant urinary tract obstruction. Clin Radiol. 1993;47(1):32-35.

30. Kligerman J. Assistência oncológica e incorporação tecnológica. Rev Bras Cancerol. 2001;47(3)239-43.

31. Reichsmn F, Levy NB. Problems in adaptation to maintenance hemodialysis. In: Coping with Physical Illness, New York: Plenum Medical Book Company 1977, apud Meleti ME. O paciente em hemodiálise. In: Angerami VA, organizador. A Psicologia no Hospital. São Paulo: Traço Editora; 1988:149-59.

32. Carter J, Ramirez C, Waugh R, Atkinson K, Coppleson M, Elliott P, et al. Percutaneous urinary diversion in gynecologic oncology. Gynecol Oncol. 1991;40(3):248-52.

33. WHOQOL Group. Study protocol for the World Health Organization project develop a quality of life assessment instrument (WHOQOL). Qual Life Res. 1993;2:153-59.

34. Pessini L. Distanásia: até quando investir sem agredir. Bioética. 1996;4. [acesso em set 2003]. Disponível em: <http://www.portalmedico.org.br/revista/bio1v4/ distanasia.html>

35. Goldim JR. Eutanásia. [acesso em mar 2000]. Disponível em: <http:/www.ufrgs.br/HCPA/hppg/eutanasi.htm>

36. Lepargneur H. Bioética da eutanásia - argumentos éticos 
em torno da eutanásia. Bioética. 1999;7. [acesso em set 2003]. Disponível em: <http://www.portalmedico.org.br/ revista/biolv7/simposio.htm>

37. Gafo J. La eutanasia: el derecho a una muerte humana. Madrid: Ediciones Temas de Hoy; 1989.

38. Kovács MJ. Autonomia e o direito de morrer com dignidade. Bioética. 1998;6. [acesso em set 2003]. Disponível em: <http://www.portalmedico.org.br/revista/bio1v6/ autodireito.htm>

39. Carrullo MAG. Qualidade de vida em cuidados paliativos [CD-ROM]. Anais da II Jornada de Cuidados Paliativos e Dor. Rio de Janeiro: CSTO/INCA; 2001.
40. Kübler-Ross E. Sobre a morte e o morrer. São Paulo: Martins Fontes; 1992.

41. MacDonald N. The interface between oncology and palliative medicine. In: Doyle D, Hanks GWS, MacDonald $\mathrm{N}$, editors. Oxford textbook of palliative medicine. Oxford: Oxford University Press; 1998:11-17.

42. World Health Organization (WHO). Cancer pain relief and palliative care: Report of a WHO Expert Committee, WHO Technical Report Series 804. Geneva: WHO; 1990.

43. Twycross RG. Mud and stars. The report of a working party on the impact of hospice experience on the church's ministry of healing. Oxford: Sobell Publications; 1991.

\section{Abstract}

This article draws on elements from bioethics to discuss the indication of hemodialysis in women with advanced cervical cancer presenting obstructive renal failure and treated at a cancer hospital. The study considers patients both with previous radiotherapy and without any type of treatment due to the advanced stage of their disease. The question is whether the patients benefited from hemodialysis (as a substitute for renal filtration) in the control of uremia caused by compression due to tumor progression. The conclusion is that hemodialysis constitutes a form of therapeutic obstinacy in the advanced stage of the disease, with no anti-tumor benefit or improvement in the patient's quality of life. The authors' aim is to encourage the discussion of the concept of futile treatment. Inclusion of the moral aspects involved in medical treatment and studied by bioethics is viewed as a way of analyzing the multi-factor impact of the disease and its treatment on patients' quality of life.

Key words: Bioethics; Medical futility; Cervical cancer; Obstructive renal failure; Hemodialysis. 